\title{
Gamificação na aprendizagem de inglês: uma análise sobre Recursos Educacionais Abertos, Motivação e Feedback
}

\author{
Gabriela Bohlmann Duarte ${ }^{1}$ \\ Curso de Licenciatura em Letras - Línguas Adicionais: Inglês, Espanhol e Respectivas Literaturas/Mestrado \\ Profissional em Ensino de Línguas, Universidade Federal do Pampa - Campus Bagé, RS, Brasil
}

Resumo: Neste artigo, apresenta-se uma análise sobre a inserção da gamificação em Recursos Educacionais Abertos (REA) para a aprendizagem de inglês a partir das definições de motivação e feedback, a fim de problematizar o uso da gamificação em tais REA. Apresentase uma análise de dados obtidos na realização de atividades gamificadas e não-gamificadas para a aprendizagem de inglês por dois grupos de alunos através da ferramenta Ensino de Línguas Online (ELO). Com base nos dados apresentados, torna-se possível constatar que embora a gamificação, enquanto característica de REA, possa ter um papel importante nas motivações de alguns alunos, não é possível generalizar essa afirmação. Além disso, é necessário considerar as formas como as informações de feedback são apresentadas nas atividades.

Palavras-chave: Gamificação; Motivação; Feedback; Recursos Educacionais Abertos (REA); Aprendizagem de inglês

Title: Gamification in English language learning: an analysis about Open Educational Resources, Motivation and Feedback

Abstract: This paper presents an analysis about the use of gamification in Open Educational Resources (OER) for English language learning. This analysis is conducted through the definitions of motivation and feedback in order to problematize the use of gamification in those OER. It is presented data collected from gamified and non-gamified activities done by undergraduate students of two groups of English students through the authoring system Ensino de Línguas Online (ELO). Based on the data, it is possible to see that even though gamification, as an OER feature, may have an important role for some students' motivations, it is not possible to generalize the efficiency of gamified activities for English learning. Besides it is necessary to consider the ways in which feedback is presented in the activities.

Keywords: Gamification; Motivation; Feedback; English Learning; Open Educational Resources (OER)

\footnotetext{
${ }^{1}$ Doutorado em Letras (Linguística Aplicada) na Universidade Católica de Pelotas. Professora Adjunta I da Universidade Federal do Pampa - Campus Bagé. Orcid: https://orcid.org/0000-0002-9044-1031

E-mail: gabrielabduarte@gmail.com
} 


\section{Introdução}

A gamificação consiste na aplicação de elementos e técnicas de design de games a experiências e contextos não caracterizados como games (DETERDING et al., 2011; McGONIGAL, 2012; WERBACH; HUNTER, 2012). Logo, atividades ou práticas que não apresentam os elementos que caracterizam games passam a tê-los e ganham uma nova forma de execução no contexto a que pertencem.

Para a realização de atividades que não são intrinsecamente motivadoras, a gamificação pode ter um papel importante na motivação. Ao se pensar em situações de ensino e aprendizagem, a gamificação pode ter um papel fundamental na motivação de alunos para a realização de tarefas e no engajamento em seus próprios processos de aprendizagem. Para que isso ocorra, torna-se necessário considerar não só os tipos de motivação envolvidos, mas também o feedback presente nas atividades gamificadas e a forma como tais atividades são elaboradas e disponibilizadas.

Em situações de ensino e aprendizagem, por exemplo, há pesquisas crescentes apontando para importâncias de games devido à experiência de jogar e de tornar essa atividade, ou missão, significativa para esse contexto. Nesses casos, há trabalhos que investigam tanto a criação de games específicos para a aprendizagem de um conteúdo quanto o uso de games já existentes, que não têm a finalidade de ensino, mas que propiciam o desenvolvimento de processos de aprendizagem em seus jogadores (MELO, 2018; BURIHAN, 2009).

Deste modo, a gamificação pode surgir como uma aliada para motivar alunos em sala de aula, visto que traz uma nova característica para esse espaço. Para o ensino de línguas, há trabalhos que demonstram como muitas pessoas aprendem inglês, principalmente, através de videogames (SAVONITTI; MATTAR, 2017; GUEDES, 2014; OLIVEIRA; CAMPOS, 2013; SANTOS, 2011; PESCADOR, 2010). Além da estrutura interna do game, que pode ser apresentada no idioma estrangeiro, há a possibilidade de interação com outros jogadores, como ocorrem com os Massive-Multiplayer Online Games². Para que os games sejam considerados boas formas de desenvolvimento das habilidades linguísticas, parte-se do pressuposto de que eles não só motivam tal aprendizagem, ainda que indiretamente, mas que também fornecem os meios adequados para que esse processo de aprendizagem ocorra.

Porém, é relevante destacar que a motivação depende de como cada pessoa se relaciona com tarefas ou atividades específicas (WERBACH; HUNTER, 2012). Assim, uma mesma tarefa pode despertar motivação em um grupo de pessoas, mas em outro grupo, não. Por isso, há atividades que podem ser gamificadas com sucesso e aplicadas a um grande público e outras, não. Na aprendizagem, é importante pensar se tais atividades, ao ganharem características de games e terem outro formato, mantendo seus objetivos iniciais, seriam de

\footnotetext{
${ }^{2}$ Games em que há a interação entre vários jogadores simultaneamente.
} 
fato motivadoras para uma turma inteira de alunos, por exemplo.

Além da motivação, outro aspecto que também é essencial para a gamificação de atividades é o feedback. O feedback refere-se às informações sobre o desempenho dos jogadores (usuários) na realização da atividade e pode o aumentar a autonomia e a motivação dos jogadores. Isso acontece porque os usuários gostam de receber um reforço sobre como eles estão indo, a fim de que consigam regular seu próprio comportamento de acordo com as medidas do seu desempenho que são fornecidas a eles (WERBACH; HUNTER, 2012).

Dessa forma, enquanto que a motivação é uma característica dos jogadores ou usuários, o feedback é uma característica das atividades ou games. Ao se pensar no uso da gamificação para a elaboração de atividades para a aprendizagem de línguas, por exemplo, sabe-se que tanto a motivação dos alunos (GARDNER, 2007; DORNEY, MACINTYRE, HENRY, 2015) quanto o feedback presente em cada atividade (CORNILLIE; CLAREBOUT; DESMET, 2012; REZAEI, DERAKHSHAN, 2011; ELLIS, 2009) desempenham um papel fundamental nos processos de ensino e aprendizagem. Logo, torna-se relevante investigar como os alunos percebem as características de games, o feedback e a motivação em atividades elaboradas para a aprendizagem de inglês.

Além disso, a partir da gamificação, torna-se possível criar atividades que sejam Recursos Educacionais Abertos (REA), isto é, que sejam disponibilizadas online, com acesso gratuito - isto é, sem que seja cobrado um valor para o acesso ao recurso em específico - , para que professores possam usá-las e adaptá-las, se necessário. Esses recursos, segundo a Unesco ${ }^{3}$, podem ser introduzidos com uma licença aberta e podem ser desde livros didáticos até currículos completos, com notas, vídeos, áudios, etc. Desta forma, esses materiais ficam disponibilizados na rede e podem sofrer alterações de acordo com os objetivos de cada professor, para que se tornem compatíveis às necessidades de seus contextos de ensino.

Embora os REA existam sem a presença da gamificação, a partir da sua implementação, tais recursos podem propiciar uma maior motivação aos seus usuários com essa estratégia tecnológica e de design. É importante pensar, assim, não só na inserção das características de games e na transformação dessas atividades em games, mas também em como essas atividades, enquanto REA, apresentam características que vão ao encontro de uma proposta que envolve aspectos tanto técnicos e de design quanto pedagógicos, especialmente na área de ensino e aprendizagem de línguas. Torna-se relevante pensar nesses REA gamificados a partir das possibilidades oferecidas pela gamificação, como a motivação ao longo da realização dessas atividades - em oposição às atividades não-gamificadas - e as percepções dos alunos ao feedback nessas atividades.

Deste modo, o objetivo deste artigo é discutir a gamificação a partir das definições de

\footnotetext{
${ }^{3}$ Open Educational Resources (OER) are teaching, learning and research materials in any medium - digital or otherwise - that reside in the public domain or have been released under an open license that permits no-cost access, use, adaptation and redistribution by others with no or limited restrictions. Disponível em: <https://en.unesco.org/themes/building-knowledge-societies/oer> Acesso em: 02 Jun. 2019.
} 
motivação, feedback e REA, a fim de problematizar o seu uso em situações de ensino e aprendizagem de línguas. Para tal, propõe-se uma discussão teórica junto com dados obtidos na pesquisa de doutorado da autora (DUARTE, 2017; 2018). Tais dados referem-se à realização de atividades gamificadas e não-gamificadas para a aprendizagem de inglês por dois grupos de alunos - através da ferramenta Ensino de Línguas Online (ELO), a qual propicia a elaboração de atividades, consideradas REA, que podem ser gamificadas ou não-gamificadas.

A seguir, será apresentado um panorama teórico sobre a gamificação e a sua utilização em atividades voltadas ao ensino de línguas e serão abordadas questões referentes à motivação e ao feedback, tanto quanto à gamificação quanto ao processo de aprendizagem; após, serão discutidos alguns aspectos teóricos e conceituais quanto aos Recursos Educacionais Abertos (REA) e, por fim, serão apresentados alguns dados coletados e analisados na pesquisa de doutorado da autora a fim de exemplificar e discutir as questões teóricas apresentadas. Nas considerações finais deste trabalho, busco refletir sobre os aspectos envolvidos na escolha da gamificação como característica que pode estimular a motivação dos alunos e que pode ser inserida em REA.

\section{Gamificação, motivação e feedback: revendo conceitos}

De acordo com Deterding et al. (2011b), a gamificação é um "termo guarda-chuva informal para o uso de elementos de videogames em sistemas não-gamificados para aumentar a experiência e o engajamento do usuário". Ela representa, assim, não só novas formas de realização de atividades diversas, mas também novas possibilidades de pesquisa no meio acadêmico. Já Werbach e Hunter (2012) salientam que as atividades gamificadas não podem perder seu objetivo principal, de modo que a gamificação não pode ser uma forma de fuga do mundo real, mas sim uma opção que visa ao engajamento mais profundo na realização da atividade em questão.

McGonigal (2012) destaca que os games conquistam cada vez mais jogadores e que eles ajudam na resolução de problemas, devido a fuga da realidade propiciada por eles. Ela destaca que os videogames, em geral, têm quatro características predominantes: há uma meta, há regras, há um sistema de feedback e há a participação voluntárias dos jogadores. Esses elementos envolvem tanto o game em si quanto a forma como os jogadores o jogam. $A$ meta e a participação voluntária dos jogadores, por exemplo, são elementos que relacionados à motivação para a realização da atividade. Já as regras e o sistema de feedback fazem parte da estrutura interna do game.

Com relação à motivação, Werbach e Hunter (2012) afirmam que ela ocorre quando há vontade de fazer alguma coisa por parte de alguém. Os autores diferenciam a motivação intrínseca (querer fazer alguma coisa) de motivação extrínseca (sentir que é necessário fazer alguma coisa). A primeira motivação pode-se referir, por exemplo, aos alunos que buscam um curso livre de Inglês ou Espanhol porque, de fato, gostam dessas línguas e dessas culturas e 
têm vontade de aprendê-las, sem que haja nenhuma pressão externa para que isso aconteça. Já a segunda motivação refere-se aos alunos que buscam cursos livres de língua não porque, de fato, querem aprender outro idioma, mas porque precisam disso para atingir outro objetivo, como uma promoção ou um novo emprego.

Werbach e Hunter (2012) destacam que, "no geral a motivação depende em como pessoas específicas se relacionam a tarefas específicas" (WERBACH; HUNTER, 2012, p.55). Outro aspecto relevante pontuado pelos autores é que a gamificação não trata apenas de $\mathrm{PBLs}^{4}$, isto é, aos pontos, às insígnias e aos rankings no jogo. Todas as formas de premiações são importantes, mas elas não devem interferir na motivação intrínseca dos jogadores.

Nesse sentido, Stanley (2012) afirma que, no ensino de línguas, a gamificação pode ser relevante porque a aprendizagem na escola não é algo que, normalmente, motive os alunos intrinsecamente. Com a gamificação, os alunos seriam encorajados a melhorar seu desempenho, já que jogariam ao invés de trabalhar.

Contudo, alguns autores apontam que haveria uma diferença entre a gamificação e a criação de um design de game ou de um design para experiências em game ${ }^{5}$ (DETERDING et al., 2011a; 2011b; DETERDING, 2014; 2016; DICHEV et al., 2014). Enquanto que a gamificação consistiria somente na adição de características de games a atividades que não são games, especialmente dos PBLs, a criação de um gameful design implicaria no propiciamento de experiências que são vividas no jogo e que estariam ligadas à motivação intrínseca, como o sentimento de realização ou progresso, de emoções positivas, de significados e de relações.

Para Dichev et al. (2014), o design de games é a criação de toda a experiência de games em ambientes que não são games. Segundo o autor, os elementos de games são usados para melhorar a experiência na tarefa, sem que haja um foco neles apenas como elementos motivadores. Deste modo, há não só a alteração nas características de games adicionadas na tarefa ou na atividade, mas também a alteração de toda a experiência na realização dessas tarefas ou atividades.

Visto que a motivação é um fator relevante para a implementação ou não da gamificação, torna-se relevante destacar algumas definições de motivação na aprendizagem de línguas. Embora haja as definições de motivação integrativa e instrumental (GARDNER; LAMBERT, 1972), as quais, dentro da aprendizagem de línguas, vão ao encontro das definições de motivação intrínseca e extrínseca, respectivamente, Gardner (2007) apresenta as diferenças entre a motivação da aprendizagem de línguas e a motivação da sala de aula.

A primeira é forma geral de motivação que se relaciona a qualquer contexto ou oportunidade de aprendizagem de outras línguas. Já a segunda refere-se à motivação de sala de aula ou em outra situação específica, de modo que o foco encontra-se na forma como os alunos percebem as tarefas que devem ser realizadas. Essa motivação é influenciada por

\footnotetext{
${ }^{4}$ No original: Points, Badges and learderboards

${ }^{5}$ No original: Gameful design ou design for gameful experiences
} 
vários fatores associados à aula de língua, como os materiais, a sala de aula, os colegas ou o professor, por exemplo.

Porém, Gardner (2007) também pontua que a intensidade da motivação, em um sentido mais amplo, parece ser mais importante que o tipo de motivação. $O$ autor ainda aponta que além da intensidade da motivação, há também componentes comportamentais, cognitivos e afetivos que influenciam os processos de ensino e aprendizagem.

Dörney, Maclntyre e Henry (2015) partem da teoria de sistemas dinâmicos para propor a definição de motivação. De acordo com os autores, a motivação muda ao longo do tempo, de modo que "se nós queremos entender a motivação (...), nós temos que concebê-la como um processo ao invés de estados" (DÖRNEY; MACINTYRE; HENRY, 2015, posição 458 ${ }^{6}$ ). Além disso, os autores ressaltam que o contexto não pode ser considerado apenas como uma "outra" variável no estudo da motivação, mas sim como um elemento com o qual o aprendiz estabelece uma relação envolvente e dinâmica.

A partir dessa perspectiva, estabelece-se a existência de uma relação extremamente importante entre o contexto de qualquer interação, em situações de aprendizagem, o aprendiz e a sua motivação para a aprendizagem. Além disso, torna-se possível compreender a motivação como um processo que está em constante movimentação e que se altera a cada nova interação e de acordo outros fatores, ao invés de uma característica estática, que não sofre mudanças. Assim, entende-se que a motivação é um processo individual, característico de cada contexto, momento e pessoa.

É importante destacar que a escolha pelo uso da gamificação ou o uso de design de game poderia ter uma influência no tipo de motivação e engajamento propiciados pela atividade. Neste trabalho, o foco recai sobre a gamificação e, como exemplos, são trazidos dados de uma investigação conduzida pela autora em sua pesquisa de doutorado (DUARTE, 2017; 2018).

Por fim, o feedback é um aspecto relevante tanto para os games e para a gamificação quanto para os processos de ensino e aprendizagem de línguas. Werbach e Hunter (2012), ao abordarem a gamificação, ressaltam que o feedback informa aos jogadores ou usuários informações sobre seu desempenho na atividade ou tarefa em questão, de modo que eles podem acompanhar sua evolução e regular o seu comportamento.

O feedback, no processo de aprendizagem de línguas, tem um papel essencial (CORNILLIE; CLAREBOUT; DESMET, 2012; REZAEI, DERAKHSHAN, 2011; ELLIS, 2009). Segundo Ellis (2009), o feedback é visto como um estímulo para a motivação do aprendiz e uma forma de assegurar a sua acurácia linguística (ELLIS, 2009, p.3). Deste modo, quando os alunos têm um alto nível de motivação na sala de aula, o feedback pode ser considerado como um aliado necessário e natural, devido ao seu papel; porém, para aqueles alunos que não têm essa motivação, o cuidado, por parte do professor, sobre como passar essa informação aos alunos torna-se mais

\footnotetext{
${ }^{6}$ Apresenta-se posição ao invés de página por se tratar de uma obra lida em sua versão Kindle.
} 
importante.

Há dois tipos de feedback que pode ser dado em situação de ensino e aprendizagem: o feedback positivo e o feedback negativo. O feedback positivo é dado quando as produções dos alunos são adequadas e, normalmente, é bem recebido pelos alunos. Já o feedback negativo é essencialmente corretivo e é dado aos alunos quando suas produções são inadequadas. Ele se refere às informações sobre o desempenho dos aprendizes de outras línguas que possam estimular seu processo de aprendizagem (CORNILLIE; CLAREBOUT; $D E S M E T, 2012)$. De acordo com Ellis (2009), embora haja divergências quanto à necessidade de correção dos erros, ou quanto à forma, o momento da correção ou os tipos de erros que devem ser corrigidos, elas dependem muito de cada contexto de aprendizagem.

Ao se pensar em atividades gamificadas, o feedback também é fundamental, tanto com relação ao desempenho linguístico dos alunos, no caso da aprendizagem de línguas, quanto na execução do desafio proposto pela atividade. Por isso, é um aspecto que deve ser considerado em ambas as perspectivas que culminam no objetivo final da implementação da gamificação. A partir dos aspectos destacados por Werbach e Hunter (2012), sabe-se que a motivação, os desafios e as possibilidades propostos são fundamentais para se considerar a gamificação como um recurso que pode influenciar positivamente a aprendizagem. Além disso, o feedback dentro de um contexto com características de games pode assumir uma forma diversa, a qual pode ser mais bem aproveitada pelos indivíduos.

A seguir, é apresentada uma revisão sobre Recursos Educacionais Abertos (REA), a fim de discutir, posteriormente, as possibilidades que a gamificação introduz a partir de dados referentes à realização de atividades por aprendizes de inglês através da ferramenta Ensino de Línguas Online (ELO).

\section{Recursos Educacionais Abertos (REA)}

Nesta seção, apresenta-se a definição de Recurso Educacionais Abertos (REA) e um panorama histórico de uso do termo, além de uma comparação dessa definição com as definições de objetos de aprendizagem (HILTON et al., 2011; WILEY, 2008; LEFFA, 2006; BANNAN-RITLAND; DABBAGH; MURPHY, 2000) e de objetos de aprendizagem de línguas (OAL) (VETROMILLE-CASTRO et al., 2012). Neste trabalho, os REA tornam-se fundamentais porque permitem a abertura de atividades para a aprendizagem de inglês, tanto em termos de acesso quanto de adaptação. A comparação entre REA e OA é relevante devido aos usos de ambos os termos para a criação de tais atividades.

Recursos Educacionais Abertos (REA) são materiais de ensino e aprendizagem que estão disponíveis na Internet e são acessíveis para todos, sem custos financeiros. De acordo com a Unesco, os REA são: 
os materiais de ensino, aprendizagem e investigação em quaisquer suportes, digitais ou outros, que se situem no domínio público ou que tenham sido divulgados sob licença aberta que permite acesso, uso, adaptação e redistribuição gratuitos por terceiros, mediante nenhuma restrição ou poucas restrições. (UNESCO, 2012).

A criação ou o desenvolvimento de REA implica na a (co)criação, o compartilhamento, a remixagem, o reaproveitamento, a (re)utilização e a colaboração entre os autores e os materiais (COOPERMAN, 2013). Segundo Cooperman (2013), para que sejam criados REA, é necessária uma intencionalidade educacional, referente à construção do conhecimento e aos objetivos da aprendizagem, às tecnologias utilizadas e às possibilidades de reuso.

Okada et al. (2012) apresentam cinco princípios, definidos por Littlejohn (2003), que devem ser considerados para o desenvolvimento de REA: objetivos de aprendizagem, claros e contextualizados, conteúdo granular bem descrito, princípios para a acessibilidade, metadados flexíveis e oportunidades para o discurso significativo. Há, deste modo, uma preocupação não só com os aspectos técnicos no desenvolvimento de tais recursos, mas também com os aspectos pedagógicos, os quais estão voltados ao seu uso e ao conteúdo, bem como às possíveis reutilizações.

É relevante destacar que, segundo o relatório publicado pelo Centro de Pesquisa em Educação e Inovação da Organização para Cooperação Econômica e Desenvolvimento (OECD), em 2007, embora a implementação de REA possa provocar uma confusão entre os limites da aprendizagem formal e da informal, ela pode também contribuir para uma fonte mais diversificada de materiais de aprendizagem. Ainda para a OECD (2007), os REA devem incluir um conteúdo a ser aprendido, que pode ser apresentado em cursos inteiros, conteúdos de módulos, objetos de aprendizagem, coleções ou revistas; ferramentas, que se referem ao software para o desenvolvimento, uso, reuso, sistemas de administração da aprendizagem e do conteúdo, ferramentas para desenvolvimento de conteúdo; e comunidades de aprendizagem on-line. Além disso, a abertura dos REA abrange tanto a disponibilidade gratuita online quanto o menor número possível de restrições quanto ao uso do recurso, sejam elas técnicas, legais ou financeiras.

Ainda com relação aos recursos educacionais abertos, há autores que relacionam a crescente inclusão das mídias digitais em situações de ensino aprendizagem ao discurso de falência do sistema escolar (AMIEL, 2012; ROSSINI; GONZALEZ, 2011). Para eles, embora os REA representem novas possibilidades e propiciem modelos híbridos de ensino e aprendizagem, não se justifica tal discurso de falência pela existência desses recursos. Porém, os REA podem transformar alguns elementos considerados mais tradicionais da escola.

De acordo com Rossini e Gonzalez (2012), é preciso que haja uma política de inclusão digital nas escolas para que seja possível o desenvolvimento dos REA, com licenças livres. Além disso, os professores deveriam ser capacitados e reconhecidos pela autoria dos REA. Já para Amiel (2012), a abertura dos REA pode gerar uma postura crítica de todos os envolvidos no processo de ensino e aprendizagem, bem como a possibilidade de experimentar atividades 
diferentes em situações diferentes de aprendizagem.

Ao se discutir tanto a definição quanto as características de REA, apresentaremos também a definição de objetos de aprendizagem (OA) e, posteriormente, de objetos de aprendizagem de línguas (OAL). Essa apresentação é necessária porque ambos os termos (OA e REA) referem-se a definições muito próximas. Segundo Mallmann e Nobre (2015), "a partir dos anos 2000 os OA vinham evidenciados com determinadas características (interatividade, reusabilidade) enquanto que já se estava avançando para a terminologia dos Recursos Educacionais Abertos (REA)" (p.626).

Um objeto de aprendizagem é, para Wiley (2008), um recurso digital que pode ser reusado para desenvolver o processo de aprendizagem. Já um REA é "um objeto de aprendizagem que pode ser livremente usado, reusado, adaptado e compartilhado" (p.346). Desta forma, a diferença entre OA e REA para o autor é a característica da abertura, a qual permite o compartilhamento e a adaptação.

Já para Hilton et al. (2011), os REA são caracterizados pela existência de quatro "Rs": o reuso, referente ao nível mais básico de abertura; a redistribuição, que é o compartilhamento com outras pessoas; a revisão, que abrange qualquer tipo de mudança na forma ou conteúdo do REA; e o remix, referente à possibilidade de combinar dois ou mais recursos para criar um novo REA. Em 2014, David Wiley ${ }^{7}$ apresentou o quinto " $R$ ", denominado reter, o qual se refere ao armazenamento, gerenciamento e duplicação de conteúdo.

Segundo Leffa (2006), há quatro características técnicas de objetos de aprendizagem: a granularidade, que se refere ao tamanho do objeto e a consequente facilidade de uni-lo a outro $\mathrm{OA}$ a fim de criar um novo; a reusabilidade, referente à possibilidade de usar novamente ou de adaptar o OA; a interoperabilidade, característica próxima à reusabilidade, refere-se à adaptabilidade do OA a diferentes sistemas e plataformas; por último, a recuperabilidade, que é a forma como um OA pode ser acessado pelos interessados.

Todas essas características estão voltadas apenas aos aspectos técnicos dos OA, sem enfoque na questão pedagógica. Leffa (2006) aborda também a neutralidade teórica, referente ao fato de que não há teorias de aprendizagem por trás da elaboração de OA. É um aspecto discutido na área, mas que se torna relevante para que os objetivos dos OA sejam atingidos, bem como as oportunidades de discurso significativo, conforme Littlejohn e Shum (2003).

Deste modo, os autores apresentados até aqui tratam de características de OA e de REA, as quais podem ser consideradas complementares. Porém, Vetromille-Castro et al. (2012; 2013), a partir das características de objetos de aprendizagem apresentadas por Leffa (2006) e da neutralidade teórica, discutem as formas com as quais os aspectos pedagógicos

\footnotetext{
7 Material criado e publicado pelo autor, gratuitamente, em blog pessoal, sob licença Creative Commons Attribution 4.0.
} 
poderiam ser abordados objetos de aprendizagem. Com relação à lacuna teórica, a qual já foi problematizada por autores como Leffa (2006) e Bannan-Ritland, Dabbagh e Murphy (2000), os autores acreditam que deve haver uma fundamentação teórica referente ao aspecto pedagógico do OA.

Nesse sentido, os autores propõem a definição de Objetos de Aprendizagem de Línguas (OAL), baseada em princípios das abordagens comunicativa e colaborativa de aprendizagem (CANALE e SWAIN, 1980; DILLENBOURG, 1999) e nos aspectos de usabilidade pedagógica (VETROMILLE-CASTRO, 2003). Os autores fazem uma releitura dos princípios comunicativos de Canale e Swain (1980), adaptados para os OAL. Dessa forma, os OAL devem integrar as competências gramatical, sociolinguística e estratégica, proporcionar oportunidades reais e significativas de comunicação na língua alvo, sem deixar de atentar às questões formais, e apresentar aspectos culturais, linguísticos e sociais da língua (VETROMILLE-CASTRO et al., 2012).

Deste este modo, a definição de OAL engloba aspectos pedagógicos, os quais tem a mesma importância que os aspectos técnicos e, por isso, devem ser considerados para a elaboração de atividades para aprendizagem de línguas. Logo, a granularidade, a reusabilidade, a interoperabilidade e a recuperabilidade devem abarcar não só as características técnicas dos objetos de aprendizagem, mas também questões referentes aos aspectos pedagógicos.

Além disso, apesar de não haver ainda uma discussão quanto à abertura desses OAL, especialmente referente ao acesso, acredito que seja relevante pensar no desenvolvimento de REA para a aprendizagem de línguas a partir das características de OAL. Os REA teriam, assim, as mesmas preocupações referentes aos aspectos pedagógicos que os OAL já têm, buscando atender aos princípios da abordagem comunicativa de ensino de línguas. A partir das possibilidades de abertura e de adaptação, os REA apresentariam um cuidado especial ao aspecto educacional, de modo que questões relativas à motivação ou ao feedback seriam também pensadas nesse viés.

Por fim, retoma-se, ainda, que o uso de REA representa novas possibilidades em situações de ensino e aprendizagem. Deste modo, a partir das devidas considerações quanto aos aspectos pedagógicos, de design e de cada contexto de utilização, os REA podem mobilizar os docentes no processo de produção e autoria e de escolha de materiais disponíveis, bem como os discentes no processo de aprendizagem que considere os meios digitais que podem já fazer parte do seu dia a dia.

Com base no que foi apresentado nesta seção, percebe-se que são vários os aspectos que precisam ser considerados para a elaboração de REA. Quando afirmamos a necessidade de se pensar em REA a partir das características de OAL, buscamos enfatizar a relevância da usabilidade pedagógica, além da usabilidade de design, a partir dos princípios comunicativos para o ensino de línguas. Além disso, nessa mesma perspectiva, a interoperabilidade também se torna importante, pois visa ao maior aproveitamento dos REA por outros professores ou 
pelos mesmos em outros contextos. A abertura também é fundamental porque pode possibilitar o compartilhamento dos materiais e a adaptação desses conteúdos, com mudanças de acordo com os estudantes, a escola, a cidade ou país e o momento em que serão usados.

Na pesquisa de doutorado realizada por Duarte $(2017,2018)$, foi utilizada a ferramenta Ensino de Línguas Online $(E L O)^{8}$, a qual possibilita a criação e a realização de atividades que são REA e que apresentam as características de OAL já destacadas. O ELO é um sistema de elaboração de atividades online, hospedado na nuvem, que não tem custos, já que é aberto, e que possibilita a reutilização e a adaptação de atividades já existentes na plataforma.

O ELO permite a elaboração de atividades que vão ao encontro de princípios comunicativos - embora isso esteja a cargo de quem as elabore -, que podem ser reutilizadas pelo mesmo professor-criador ou por outros professores que as considerem importantes para seus contextos de ensino e que podem ser adaptadas. Outra característica relevante da ferramenta ELO é a possibilidade de gamificar as atividades elaboradas. Logo, o sistema encarrega-se da gamificação, de modo que o professor pode criar uma sequência de módulos e transformá-los em um game ou atividade gamificada, de acordo com os seus objetivos para as atividades (LEFFA, 2014).

A seguir, são apresentadas duas figuras que ilustram exemplos de atividades utilizadas na pesquisa da autora. A Figura 1 é de uma atividade gamificada. Nessa versão, há um ranking de classificação e a pontuação, apresentadas na barra vertical lateral, bem como a possibilidade de escolha, pelo aluno, de um avatar. São apresentadas as conquistas, as quais são alcançadas à medida que mais atividades (ou desafios) são realizadas. Já na barra horizontal, é apresentado o progresso do aluno na atividade realizada, de modo que a cada novo módulo concluído, há o avanço na atividade.

\footnotetext{
${ }^{8}$ Disponível em: https://elo.pro.br/cloud/ . Todas as atividades elaboradas para a realização da pesquisa da autora estão disponíveis no site do ELO Cloud. Os links para cada atividade elaborada e aplicada estão disponíveis em Duarte (2017).
} 
Figura 1 - Exemplo de atividade gamificada no ELO

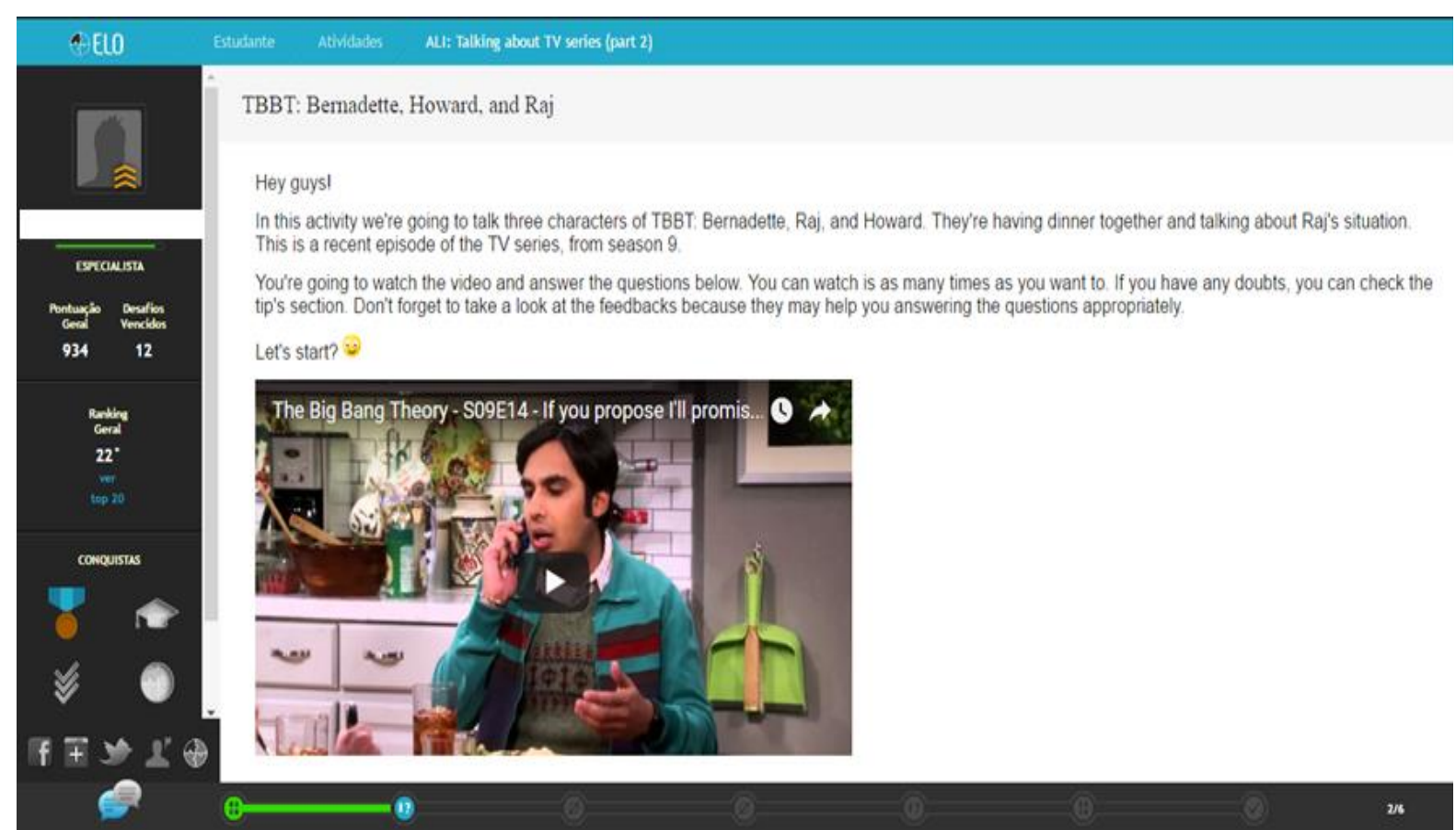

Fonte: Autora (DUARTE, 2017)

Figura 2 - Exemplo de atividade não- gamificada no ELO

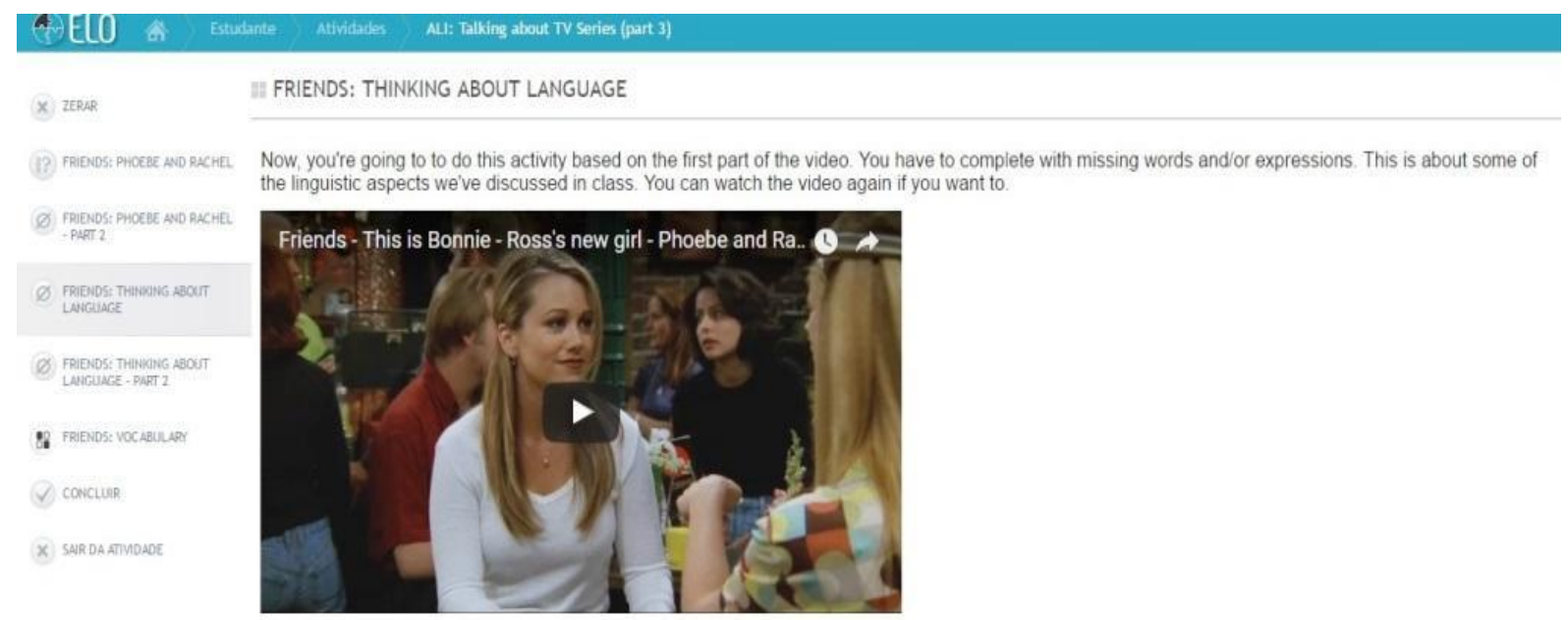

In the first part of the video, Phoebe asks Rachel about the $\square$ of setting Ross up on a date with a friend of hers. She said: "Would it be okay with you if I set Ross up on a date?". She uses a sentence to say that. Her intention is probably to know that in case Ross went out with Bonnie, Rachel would still be (9.) She would only do that if Rachel didn't mind. if she did, this wouldn't happen. So, this is an unilikely event if Rachel doesn't accept it. She probably chose that to say to Rachel

Fonte: Autora (DUARTE, 2017)

O ELO também permite que os professores elaborem o feedback para alguns de seus módulos. Desse modo, o professor tem a possibilidade de criar o feedback de acordo com o conteúdo de cada atividade e de considerar a contextualização dos aspectos temáticos e de sentido. Os módulos Múltipla Escolha (Quiz ou Dialógica) apresentam essa possibilidade, de 
forma que pode haver um feedback específico para cada uma das alternativas apresentadas, tanto as corretas quanto as incorretas. Há também outros módulos que não necessitam do feedback criado pelo professor, como o Sequência, o Cloze ou o Memória. No módulo Sequência, o aluno deve ordenar alguma sequência de palavras, frases, imagens etc. Quando a ordenação não está adequada, o sistema marca em amarelo as estruturas que estão no lugar errado. Já no módulo Cloze, o aluno tem que completar um texto com palavras ou frases que faltam. Quando ele completa com alguma palavra inadequada, o sistema rejeita a palavra, indicando pela não inserção ao texto. Por fim, no módulo Memória, como um jogo da memória tradicional, quando não se forma o par adequado, as cartas são viradas novamente, voltando à posição original.

A seguir, são apresentados alguns exemplos (Figuras 3 e 4) de feedback criados na ferramenta ELO:

Figura 3 - Exemplo de feedback corretivo específico para uma atividade de compreensão leitora em língua inglesa

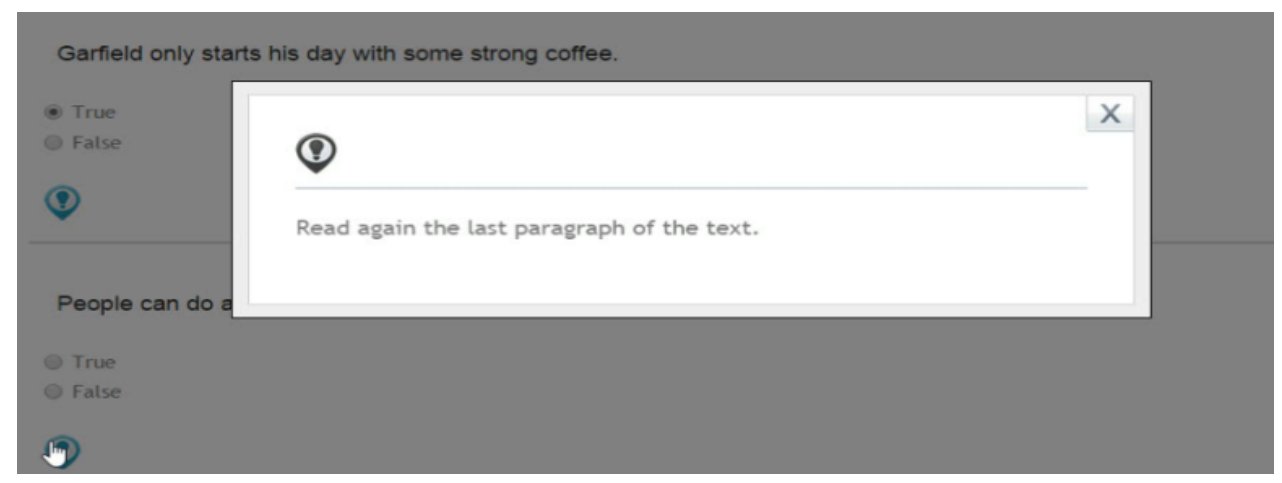

Fonte: Autora (DUARTE, 2017)

Figura 4 - Exemplo de feedback positivo para uma atividade do Módulo Memória

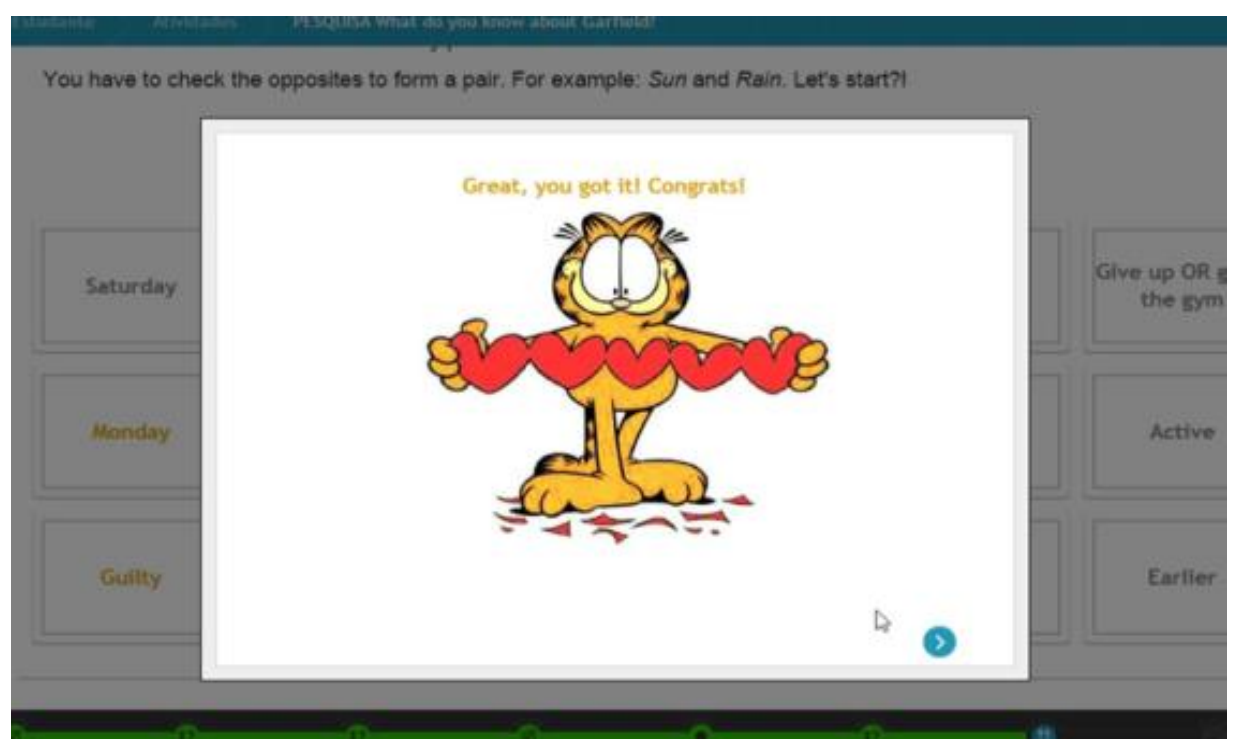

Fonte: Autora (DUARTE, 2017) 
Com isso, o sistema ELO vai ao encontro da abertura, reusabilidade e adaptabilidade já destacadas nessa seção e dos princípios pedagógicos ou dos aspectos educacionais. A partir das instruções, é possível orientar o aluno para a realização de cada módulo/atividade sem que o professor esteja presente.

Por fim, é relevante ressaltar que os REA não dependem da gamificação para existirem. Embora as características de games em recursos digitais propiciem uma semelhança maior aos tradicionais videogames e possibilitem uma experiência de competição, a gamificação é um recurso adicional. A análise proposta pela autora, em sua pesquisa de doutorado, foi considerada relevante por abordar o quanto a definição de REA, juntamente com a de OAL, e a discussão acerca dos conceitos de abertura, reutilização e adaptabilidade são importantes para uma proposta de ensino e aprendizagem que possa ser levada e acessada pelos alunos e que também possa propiciar uma liberdade de escolha aos professores, de acordo com seus objetivos.

Além disso, tal pesquisa também reitera que a gamificação pode ser relevante para a motivação de alunos, mas também demonstra que há outros aspectos que precisam ser levados em consideração, os quais serão apresentados e discutidos, a partir da análise dos dados e dos aspectos teóricos abordados até então.

\section{Realização de atividades gamificadas e atividades não-gamificadas: percepções e aspectos relevantes}

A fim de pontuar os aspectos discutidos nas seções anteriores referente à gamificação, à motivação e ao feedback, serão apresentados alguns dados coletados para a pesquisa de doutorado da autora. Esses dados provêm de dois grupos de alunos de cursos de Licenciatura em Letras, com habilitação em Inglês, os quais realizaram atividades gamificadas e nãogamificadas. Dentre os objetivos da coleta, estava o de averiguar a percepção dos discentes quanto às diferenças entre as atividades gamificadas e não-gamificadas, a presença do feedback e à suas motivações para a realização das atividades. A análise dos dados foi realizada a partir de uma abordagem qualitativa e quantitativa, visto que os dados numéricos que foram gerados também foram interpretados com um viés qualitativo (BAUER; GASKELL; ALLUM, 2002)

Na pesquisa realizada por Duarte $(2017 ; 2018)$, houve a divisão dos grupos de alunos em dois estudos: Estudo 1 e Estudo 2. Além disso, para cada estudo, houve a aplicação de dois questionários. O primeiro foi aplicado antes da realização das atividades e o segundo, após. A seguir, serão apresentados alguns dados relevantes e pontuais de ambos os estudos, com o enfoque nos aspectos referentes ao feedback e a motivação para a realização das atividades. O objetivo da análise apresentada aqui é averiguar de que forma a gamificação influenciou ou 
não na motivação dos alunos para a realização de atividades para aprendizagem de inglês e verificar a percepção desses alunos quanto às informações de feedback nessas atividades.

No Estudo 1, houve a participação de quatro discentes, os quais realizaram as atividades gamificadas e não-gamificadas voluntariamente. As atividades foram realizadas pelos alunos na companhia da pesquisadora, com a gravação do processo de realização de atividades de cada aluno, bem como de seus comentários, além das respostas aos questionários. Já no Estudo 2, houve a participação de oito alunos, do total de 14 alunos que realizaram as atividades. Embora a participação na pesquisa tenha sido voluntária, a realização das atividades não foi. As atividades foram aplicadas a uma turma de alunos e fazia parte da avaliação da disciplina da qual a pesquisadora foi a professora ministrante. Além disso, os alunos escolheram, previamente, a temática das atividades: três séries de TV americana. Logo, ao se pensar na motivação extrínseca desses alunos, deve-se considerar que havia o componente "avaliação" (ou nota), o qual influenciou a realização das atividades. Por isso, considerou-se a percepção dos alunos quanto às diferenças nas atividades e se essas possíveis diferenças poderiam ter influenciado na motivação para cumprir a tarefa exigida pela disciplina.

O primeiro aspecto pontuado aqui é a percepção de alguns alunos quanto às atividades desenvolvidas no Módulo Memória. No Estudo 1, uma aluna afirmou, enquanto realizava as atividades, que as barras que representam as informações de pontuação e de percurso do game, nas atividades gamificadas, deixavam-na nervosa. Essa mesma aluna já havia afirmado que costumava jogar videogames; quando questionada sobre como se sentia quando apareciam as informações de desempenho no game, ela afirmou que também não gostava que "a irrita quando aparecem as mortes que comete" [no game Call of Duty].

Já o segundo aspecto refere-se ao fato de que, quando questionada sobre a gamificação, essa mesma aluna afirmou que achou que participação na pesquisa seria "apenas para que completasse atividades em inglês", e não para que jogasse. Destaca-se que todos os dados analisados para essa pesquisa tiveram seus usos consentidos pelos alunos participantes. Logo, essa aluna foi esclarecida quanto aos objetivos da pesquisa e às ações esperadas. Porém, provavelmente, ela apresenta, de acordo com esse relato, uma interpretação do que seria a realização de atividades gamificadas e não-gamificadas, a qual não incluía a ideia de jogar, mas sim de completar atividades para a aprendizagem de inglês. Entretanto, quando essa aluna realizou os módulos Memória, ela afirmou que gostava desse jogo e que era bastante competitiva, de modo que costuma ficar "furiosa quando perde". Logo, podemos questionar se o gosto pela competitividade no jogo da memória é diferente do gosto pela competitividade no videogame. Sabe-se que o jogo da memória é um jogo comumente usado em sala de aula, para a aprendizagem de línguas. Porém, o conjunto de atividades gamificadas também era voltado à aprendizagem de inglês na pesquisa. Podem ser consideradas, assim, como atividades lúdicas e prazerosas, que contêm elementos importantes para a aprendizagem neste contexto específico. 
Provavelmente, para a aluna em questão, essas atividades gamificadas deveriam fazer parte de um conjunto de atividades que não visassem ao ensino, mas sim ao lazer; já o jogo da memória poderia estar inserido num contexto de ensino, como muitas vezes acontece. Em outras palavras, o jogo da memória é, assim, uma prática normal ou esperada no contexto de ensino, enquanto que o game não é uma prática normal ou esperada para a aprendizagem dela. Desse modo, as atividades gamificadas não proporcionaram, para essa aluna, a mesma intensidade de motivação (GARDNER, 2007) que as atividades não-gamificadas, no contexto de aprendizagem, ou que os videogames que está acostumada a jogar, no contexto de lazer. Além disso, o fato de ela ter afirmado que esperava apenas uma participação na pesquisa para realizar atividades de inglês, ao invés de jogar, pode demonstrar uma alta intensidade de motivação dessa aluna para a aprendizagem de inglês.

Da mesma forma, no Estudo 2, alguns alunos também consideraram os Módulos Memória como as atividades gamificadas. Com isso, percebe-se que os alunos não conseguiram diferenciar a gamificação, enquanto característica que os aproximaria de um game digital, e o game ou jogo (da memória, neste caso), que é muitas vezes comum em aulas de língua. A ideia de game é relacionada ao jogo da memória ao invés das características de gamificação presentes nas atividades. É possível pensar que tais características, as mesmas dos games que jogam em situações de lazer, não seriam esperadas ou aceitas no contexto acadêmico. $\mathrm{Ou}$, ainda, que os games que esses alunos costumam jogar (conforme respostas afirmativas no questionário) são muito mais complexos - em termos de design e desafios - do que as atividades gamificadas que realizaram. Nesse sentido, é provável que os alunos reconheciam o jogo da memória como um game que pode aparecer em situações de ensino e aprendizagem.

Já com relação ao desempenho dos alunos e as suas preferências, apresento alguns dados do Estudo 2. Houve, no geral, um melhor desempenho dos alunos participantes nas atividades gamificadas, com uma média de $66,3 \%$ de acertos, do que nas atividades nãogamificadas, com uma média de $58,6 \%$ de acertos. A porcentagem de acertos é calculada pelo próprio sistema, ao final de cada atividade, de modo que o professor tem acesso a esses dados.

Dos oito alunos que participaram desse estudo, cinco apresentaram um melhor desempenho nas atividades gamificadas. Porém, desses cinco alunos, apenas três afirmaram, no segundo questionário respondido, que se sentiram mais motivados ao realizar as atividades gamificadas, em comparação às atividades não-gamificadas. Os outros alunos ou tiveram um melhor desempenho nas atividades gamificadas, mas não se sentiram mais motivados, ou nem tiveram melhor desempenho e nem se sentiram mais motivados. Assim, pode-se constatar que o melhor desempenho dos alunos nas atividades gamificadas, representado pela pontuação, não indica, necessariamente, a percepção de uma maior motivação para a sua realização. 
Outro fator que pode ser levantado neste aspecto refere-se à concepção de jogo/game desses alunos, a qual pode ter influenciado a sua percepção. Conforme já apontado, a gamificação, nas atividades realizadas pelos alunos, caracterizou-se pela inserção de pontos, insígnias e medalhas ( $P B L S)$. Neste caso, a experiência do game ocorre a partir dessas características. Porém, há autores que propõem a criação de um design de games, que seria a alteração na experiência de realização de atividades ou tarefas (DICHEV et al., 2014). Com base nesse dado, é possível pensar que a gamificação pode não ser suficiente para oferecer a mesma experiência que um design de games ofereceria, a qual poderia estar mais próxima a concepção de game que os alunos têm.

Nesse sentido, é relevante destacar o caso de dois alunos que, apesar de não terem percebido inicialmente as diferenças entre as atividades gamificadas e não-gamificadas, sentiram-se mais motivados com a realização das atividades gamificadas. Para uma aluna, a motivação maior foi causada porque a "barrinha fica mais visível" e lembrou-a do game que costuma jogar (Minions). A barrinha que ela se refere é a indicação de progresso em cada módulo até a conclusão da atividade. Ela provavelmente percebeu o design diferente, mas não reconheceu as atividades como diferentes. Quando expliquei, em aula, que havia diferença entre as atividades, ela percebeu a diferença entre o design da atividade e a semelhança com o jogo que ela joga e gosta. Essa aluna, em particular, apresentou um maior desempenho nas atividades gamificadas (média de $81 \%$ de pontuação) do que nas atividades não-gamificadas (média de 71\%), o que vai ao encontro do fato de que ela se sentiu mais motivada nas atividades gamificadas. Desse modo, embora algumas características de games tenham sido marcantes e tenham tido um efeito positivo no desempenho desses alunos, a percepção das atividades enquanto games não foi clara.

A compreensão dos alunos, no Estudo 2, sobre as suas preferências e a motivação para a realização das atividades recaiu mais sobre a temática e o tipo de atividade do que a presença da gamificação. Nesse estudo, houve uma preferência maior pelas atividades que eram da série de TV Friends do que pelas atividades sobre Game of Thrones ou The Big Bang Theory. Nos questionários, os alunos afirmaram que essa preferência ocorreu pela dificuldade que sentiam com os vídeos selecionados. Além disso, havia também atividades gramaticais, as quais abrangiam o conhecimento metalinguístico ${ }^{9}$. Essas atividades foram elaboradas também a partir dos vídeos utilizados. A partir das respostas aos questionários e ao desempenho dos alunos nas atividades gramaticais, foi possível considerar que os alunos não apresentaram um alto nível de motivação para essas atividades, em comparação às atividades que eram voltadas à compreensão oral dos vídeos das séries de TV elencadas.

Com base nesse aspecto, retoma-se que a motivação não é uma característica fixa dos indivíduos (DORNEY, MACINTYRE, HENRY, 2015). Logo, à medida que diferentes situações emergem, as motivações mudam, de modo que, neste estudo, os tanto os aspectos temáticos

\footnotetext{
${ }^{9}$ Visto que os alunos participantes da pesquisa eram discentes de curso de Licenciatura em Letras, havia um trabalho voltado a aspectos estruturais e/ou gramaticais da língua inglesa.
} 
quanto os aspectos linguísticos foram fundamentais para que os alunos percebessem o processo de realização de atividades de formas diversas.

Além disso, destaco que, no Estudo 2, cinco, dos oito participantes, responderam, no segundo questionário, que sentiram falta das informações de feedback. Como justificativas, houve uma aluna que disse que precisa "do feedback pra se sentir mais motivada e acho que faltou um pouco"; outra aluna afirmou que sentiu falta, mas por parte da professora em sala de aula, pra que pudesse "analisar mais

calmamente e de maneira focada"; outro aluno também disse que sim "para saber se estou indo bem".

Contudo, destaca-se a resposta de uma aluna que, embora tenha afirmado que sentiu falta na parte gramatical porque "parecia que não sabia fazer nada" , também relatou que a mensagem que aparecia quando acertava alguma atividade "era bem legal". Logo, para essa aluna, houve a percepção da mensagem final, que incentiva/motiva o aluno pelo acerto da questão. Contudo, as informações de feedback referentes ao desempenho nas atividades não foram suficientes na opinião dos alunos.

Ainda com relação ao aspecto feedback, deve-se considerar também a escolha dos módulos para essas atividades. Houve algumas atividades elaboradas no módulo Quiz, que apresentavam feedback progressivo, específico e situado para cada alternativa correta ou incorreta, proporcionando uma melhor assistência ao aluno no seu desempenho. Porém, houve também atividades elaboradas no módulo Cloze, que apresentavam apenas o feedback genérico, proporcionado automaticamente pelo sistema indicando quando as respostas não estão adequadas. Logo, as atividades elaboradas no Módulo Quiz parecem ser mais adequadas para o trabalho com os aspectos gramaticais do que as atividades elaboradas no Módulo Cloze.

A seguir, serão apresentadas as considerações finais referentes à discussão teórica a partir dos dados apresentados neste trabalho.

\section{Considerações finais}

Na discussão proposta neste artigo, é possível constatar que, apesar de os Recursos Educacionais Abertos (REA) não dependerem da gamificação para que sejam elaborados e implementados, a gamificação pode ser uma característica relevante em REA de acordo com os objetivos do professor para as atividades em questão. Ela pode ter um efeito positivo na motivação dos alunos envolvidos; porém, há outros aspectos que devem ser considerados nesta decisão.

Com relação à percepção dos alunos ao feedback, pode-se perceber que ela não foi sempre clara, visto que muitos relataram que sentiram falta dessa informação. Neste caso da 
pesquisa, pode-se pensar na característica das atividades, que eram tanto sobre a compreensão oral e/ou textual em língua inglesa, mas também sobre aspectos linguísticos (lexicais e gramaticais). Deste modo, a dificuldade de cada atividade pode ter justificado a falta da informação de feedback.

Esse fato, em especial, aponta para a necessidade de se pensar na elaboração de atividades que são feitas pelos alunos sem a presença do professor. Embora a autonomia dos discentes para buscar os conteúdos vistos em aula seja fundamental, é uma prática que, possivelmente, saia do contexto de um game - no qual os jogadores executam as tarefas do game no próprio game. Logo, atividades mais complexas, que demandam mais informações linguísticas, podem gerar esse tipo de dificuldade. Porém, salienta-se que tais questões são referentes à aplicação das atividades a grupos de alunos em contextos bem específicos e, deste modo, sabe-se que os efeitos da utilização de atividades gamificadas (inclusive do tipo de atividade) pode ser bastante característica de cada aluno ou turma.

Deste modo, a partir do que já é apontado pela literatura (DETERDING et al., 2011a; 2011b; WERBACH; HUNTER, 2012; STANLEY, 2012), essa análise demonstrou que a gamificação teve um papel importante para a motivação da aprendizagem de inglês de alguns alunos. Contudo, a influência da gamificação para tal motivação não pode ser generalizada, visto que, nos dados obtidos na pesquisa aqui apresentada, mesmo alunos que praticavam ou que já tivessem praticado letramentos em games (BUCKINGHAM; BURN, 2007; SQUIRE, 2008) - isto é, que tenham ou já tenham tido o hábito de jogar videogames como atividades de lazer - não perceberam as características da gamificação e não se sentiram mais motivados para realizar as atividades gamificadas. A opção temática e o tipo de atividade, no Estudo 2, foi mais importante para definir as preferências dos alunos.

Além disso, a gamificação foi confundida, por alguns participantes, com o Módulo Memória, o que indica a não percepção das características do game no contexto escolar e/ou acadêmico. $\mathrm{O}$ jogo da memória é um game que pertence ao contexto escolar ou acadêmico, seja ou não na forma digital. As características de games em atividades voltadas a esse mesmo contexto não são comuns e, talvez, nem sempre necessárias. Além disso, pensando naqueles alunos que jogam muito e, assim, tem práticas de letramentos em games em um nível avançado, é possível questionar se somente a presença dos $P B L s$ seria suficiente para estimulá-los da mesma forma que games mais desenvolvidos fazem.

Nesse sentido, as motivações são particulares de cada indivíduo ou grupo de alunos e de cada situação. Logo, a generalização quanto aos efeitos da gamificação, neste aspecto, torna-se problemática. Também, deve-se considerar que, em se tratando de atividades que são voltadas para a aprendizagem de línguas, além dos cuidados referentes ao design pedagógico, indo ao encontro da abordagem comunicativa no ensino de línguas, é também preciso considerar o tipo de atividade e o tipo de feedback para ela, de acordo com os objetivos do professor.

Por fim, é relevante destacar que, nas atividades analisadas neste artigo, as 
características de gamificação presentes eram apenas os $P B L s$. Porém, já há trabalhos que preconizam a importância de se criar não apenas atividades gamificadas isoladas, como foi o caso das atividades utilizadas na minha pesquisa, mas sim de se trabalhar com a criação de um design gamificado, no qual toda a experiência interativa da sala de aula ocorreria de uma forma gamificada (DETERDING, 2014; 2016; DICHEV et al., 2014). É possível que, a partir de um design gamificado, as percepções dos alunos e as suas motivações manifestem-se de formas diferentes.

\section{Referências}

AMIEL, T. Educação aberta: configurando ambientes, práticas e recursos educacionais. In: SANTANA, B.; ROSSINI, C.; PRETTO, N. L. (Orgs.) RECURSOS EDUCACIONAIS ABERTOS: práticas colaborativas e políticas públicas. 1. ed. São Paulo: Casa da Cultura Digital, 2012.

BANNAN-RITLAND, B.; DABBAGH, N.; MURPHY, K. Learning object systems as constructivist learning environments: Related assumptions, theories, and applications. In: WILEY, D. A. (Ed) The Instructional Use of Learning Objects: Online Version, 2000.

BAUER, M. W.; GASKELL, G.; ALLUM, N. C. Qualidade, quantidade e interesses do conhecimento - evitando confusões. In: BAUER, M. W.; GASKELL, G. Pesquisa Qualitativa com Texto, Imagem e Som. Petrópolis, RJ: Vozes, 2002.

BUCKINGHAM, D.; BURN, A. Game Literacy in Theory and Practice. Journal of Educational Multimedia and Hypermedia, 2007, v. 16, n.3, p. 323-349.

BURIHAN, C. M. L. A. Os videogames como recursos de ensino-aprendizagem: uma experiência nas aulas de matemática do ensino fundamental da rede pública. 2009. 112 f. Dissertação (Mestrado em Mídias Digitais) - Pontifícia Universidade Católica de São Paulo, São Paulo, 2009.

CANALE, M.; SWAIN, M. Theoretical Bases of Communicative Approaches to Second Language Teaching and Testing, Applied Linguistics, v. 1, n. 1, p. 1-47, 1980. https://doi.org/10.1093/applin/1.1.1

CORNILLIE, F.; CLAREBOUT, G.; DESMET, P. The role of feedback in foreign language learning through digital role playing games. Procedia - Social and Behavioral Sciences, n. 34, 2012, p. 49-53. https://doi.org/10.1016/i.sbspro.2012.02.011

DETERDING, C. S.; DIXON, D.; KHALED, R.; NACKE, L. From Game Design Elements to Gamefulness: Defining "Gamification". Proceedings of the 15th International Academic MindTrek Conference: Envisioning Future Media Environments, September 28-30, Tampere, Finland, 2011. https://doi.org/10.1145/2181037.2181040

DETERDING, C. S.; SICART, M.; NACKE, L.; O'HARA, K.; DIXON, D. Gamification: using game design elements in non-gaming contexts. Proceedings of the ACM CHI Conference on Human Factors in Computing Systems, May 7-12, Vancouver, Canadá, 2011. Disponível em: $<$ http://gamification-research.org/wp-content/uploads/2011/04/01-Deterding-Sicart-NackeOHara-Dixon.pdf > Acesso em: 02 Jun. 2019. https://doi.org/10.1145/1979742.1979575

DETERDING, C. S. Eudaimonic Design, or: Six invitations to rethink gamification. In: FUCHS, M.; FIZEK, S.; RUFFINO, P.; SCHRAPE, N. (Eds) Rethinking gamification. Germany: Meson Press, 
2014.

DETERDING, C. S. Make-Believe in gameful and playful design. In: Digital MakeBelieve. HumanComputer Interaction. Springer, Basel, p. 101-124. 2016. https://doi.org/10.1007/978-3-31929553-4 7

DICHEV, C.; DICHEVA, D.; ANGELOVA, G.; AGRE, G. From gamification to gameful design and gameful experience in learning. Cybernetics and Information Technologies, v. 14, n. 4, 2014. https://doi.org/10.1515/cait-2014-0007

DILLENBOURG, P. What do you mean by collaborative learning? In: DILLENBOURG, P. (Ed.) Collaborative-learning: Cognitive and Computational Approaches. Oxford: Elsevier, 1999. p. 119.

DÖRNEY, Z; MACINTYRE, P. D.; HENRY, A. (Eds) Motivational Dynamics in Language Learning. Kindle Edition. Short Run Press: Great Britain, 2015. https://doi.org/10.21832/9781783092574

DUARTE, G. B. Eventos complexos de letramentos na aprendizagem de inglês: relações entre práticas de letramentos, gamificação e motivação. 2017. 168 f. Tese (Doutorado em Letras Linguística Aplicada), Programa de Pós-Graduação em Letras, Universidade Católica e Pelotas, Pelotas, Brasil, 2017.

DUARTE, G. B. Aprendizagem de inglês a partir de Eventos Complexos de Letramentos: uma perspectiva complexa sobre a motivação e as práticas de letramentos. (CON)TEXTOS LINGUÍSTICOS, v. 12, p. 46-67, 2018.

ELLIS, R. Corrective Feedback and Teacher Development. L2 Journal, n.1, v.1, 2009. Disponível em: Acesso em: 23 set. 2014. https://doi.org/10.5070/L2.V1l1.9054

GARDNER, R. C. Motivation and Second Language Acquisition. Porta Linguarum, v. 8, p. 9-20, 2007.

GARDNER, R. C.; LAMBERT, W. Attitudes and Motivation in Second Language Learning. Rowley: Newbury House, 1972.

GUEDES, L.K. O uso de games como input para a aprendizagem de línguas. 2014. 103f. Dissertação (Mestrado em Letras). Programa de Pós-Graduação em Letras. Universidade Católica de Pelotas, Pelotas, Brasil, 2014.

HILTON, W.; WILEY, D.; STEIN, J.; JOHNSON, A. The Four R's of Openness and ALMS Analysis: Frameworks for Open Educational Resources, 2011.

LEFFA, V. J. Gamificação adaptativa para o ensino de línguas. Anais do Congreso Iberoamericano de Ciencia, Tecnología, Innovación y Educación. Artículo 499, 2014. Disponível em: <http://www.leffa.pro.br/textos/trabalhos/Gamificacao_Adaptativa_Leffa.pdf>. Acesso em: 16 out. 2019.

LEFFA, V. J. Nem tudo que balança cai: Objetos de aprendizagem no ensino de línguas. Polifonia. v. 12, n. 2, p. 15-45, 2006.

LITTLEJOHN, A; SHUM, S. B. Reusing Online Resources (Special Issue) Journal of Interactive Media in Education, n. 1, 2003. https://doi.org/10.5334/2003-1-reuse-01

MALLMANN, E. M.; NOBRE, A. M. J. F. Dos Objetos de Aprendizagem aos Recursos Educacionais (Abertos). In: IX Conferência Internacional de TIC na Educação, 2015, Braga. Atas 
da IX Conferência Internacional de TIC na educação. Braga: Universidade do Minho, 2015. v. 1. p. 620-633.

MCGONIGAL, J. Reality is broken. Tradução: Eduardo Rieche. BestSeller: Rio de Janeiro, 2012.

MELO, L. A. Caio, O Matemago: uma abordagem para uso dos videogames como ferramenta de suporte no ensino-aprendizagem de matemática. 2018. 91 f. Relatório (Mestrado Profissional em Tecnologias, Comunicação e Educação), Universidade Federal de Uberlândia, Uberlândia, 2018. Programa de Pós-graduação em Tecnologias, Comunicação e Educação. https://doi.org/10.21745/ac09-06

OECD - Organization for Economic Co-operation and Development. Giving Knowledge for free: The emergence of open educational resources, 2007. Disponível em: <http://www.oecd.org/education/ceri/38654317.pdf> Acesso em: 16 Out. 2019.

OKADA, A., MIKROYANNIDIS, A., MEISTER, I. \& LITTLE, S. "Colearning" - Collaborative Open Learning through REA and Social. In: OKADA, A. Open Educational Resources and Social Networks: Co-Learning and Professional Development. London: Scholio Educational Research \& Publishing, 2012. https://doi.org/10.4018/978-1-46660-300-4

COOPERMAN, L. Abertura. In: OKADA, A. Recursos Educacionais Abertos \& Redes Sociais. São Luís: EdUEMA, 2013.

OLIVEIRA, K. S.; CAMPOS, M. S. F. O ensino-aprendizagem de língua inglesa como LE através de videogames não didáticos. 2013. 81f. Trabalho de Conclusão de Curso (Graduação em Licenciatura em Letras). Universidade Tecnológica Federal do Paraná, 2013.

PESCADOR, C. M. Ações de aprendizagem empregadas pelo nativo-digital para interagir em redes hipermidiáticas tendo o inglês como língua franca. 2010. 142f. Dissertação (Mestrado em Educação). Programa de Pós-Graduação em Educação. Universidade de Caxias do Sul, 2010.

REZAEI, S.; DERAKHSHAN, A. Investigating Recast and Metalinguistic Feedback in Task-based Grammar Instruction. Journal of Language Teaching and Research, v. 2, n. 3, p. 655-663, 2011. https://doi.org/10.4304/iltr.2.3.655-663

ROSSINI, C.; GONZALEZ, C. REA: o debate em política pública e as oportunidades para o mercado In: Santana, B.; Rossini, C.; Pretto, N. L. (Orgs) RECURSOS EDUCACIONAIS ABERTOS: práticas colaborativas e políticas públicas. 1. ed., Salvador: Edufba; São Paulo: Casa da Cultura Digital, 2012.

SANTOS, V. R. F. Os Jogos MMORPG como Auxiliadores no Processo de Aquisição de Língua Inglesa. 2011. 121f. Dissertação de Mestrado em Linguística Aplicada. Programa de PósGraduação em Estudos Linguísticos, Universidade Federal de Minas Gerais, MG.

SAVONITTI, G. A.; MATTAR, J. Games de entretenimento para o ensino do inglês como segunda língua: características e potencial. SBC - Proceedings of SBGames, 2017. Disponível em: <https://www.sbgames.org/sbgames2017/papers/CulturaFull/174468.pdf>. Acesso em 24 Maio 2019.

SQUIRE, K. Video-game literacy: a literacy to expertise. In: J. Coiro, M. Knobel, C. Lankshear, and D. Leu (eds.) Handbook of research in New Literacies, New York, NY: Lawrence Erlbaum Associates, 2008. 
STANLEY, G. Language Teaching and learning: Online Digital Games And Gamification. 2012. Disponível em: <http://www.tesol-spain.org/uploaded_files/files/Graham-Stanley.pdf> Acesso em: 07 set. 2014

UNESCO - OECD: Policy guidelines for mobile learning. France: United Nations Educational, Scientific and Cultural Organization, 2013. Disponível em: <https://wayback.archiveit.org/10611/20160802154111/http://unesdoc.unesco.org/images/0021/002196/219641e.p df> Acesso em: 02 Jun. 2019.

VETROMILLE-CASTRO, R.; MOOR, A. M. ; DUARTE, G. B. ; SEDREZ, N. H. From Learning Objects to Language Learning Objects: Communicative Language Teaching Principles in CALL Material. International Journal of Computer-Assisted Language Learning and Teaching (IJCALLT), v. 3, p. 82-96, 2013. https://doi.org/10.4018/ijcallt.2013040105

VETROMILlE-CASTRO, R.; MOOR, A. M.; DUARTE, G. B.; SEDREZ, N. H. Objetos de aprendizagem de línguas: uma proposta. In: Rafael Vetromille-Castro; Christiane Heemann; Vanessa Ribas Fialho. (Org.). Aprendizagem de línguas - a presença na ausência: CALL, Atividade e Complexidade. 1. ed. Pelotas: Educat, 2012, v. 1, p. 241-256.

VETROMILLE-CASTRO, R. A usabilidade pedagógica e de design em materiais para o ensino a distância de inglês para leitura. Intercâmbio (PUCSP), São Paulo, v. 12, p. 145-154, 2003.

WERBACH, K.; HUNTER, D. For The Win: How Game Thinking Can Revolutionize Your Business? Wharton Digital Press: Philadelphia, 2012.

WILEY, D. A. The Learning Objects Literature. In: JONASSEN, D., SPECTOR, M. J.; DRISCOLL, M.; MERRILL, M. D.; MERRIENBOER, J. V. (Eds.) Handbook of Research for Educational Communications and Technology: A Project of the Association for Educational Communications and Technology, 3. ed., pp. 345-353, New York, NY: Routledge, 2008.

WILEY, D. A. The Access Compromise and the 5th R. Iterating toward openness - pragmatism before zeal. 5 Mar. 2014. Disponível em: <https://opencontent.org/blog/archives/3221> Acesso em: 13 out. 2019.

Recebido em: 05/06/2019

Aceito em: 18/10/2019 